\title{
Costs and where to find them: identifying unit costs for health economic evaluations of diabetes in France, Germany and Italy
}

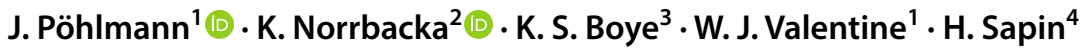

Received: 19 December 2019 / Accepted: 26 August 2020 / Published online: 6 October 2020

(c) The Author(s) 2020

\begin{abstract}
Background Health economic evaluations require cost data as key inputs. Many countries do not have standardized reference costs so costs used often vary between studies, thereby reducing transparency and transferability. The present review provided a comprehensive overview of cost sources and suggested unit costs for France, Germany and Italy, to support health economic evaluations in these countries, particularly in the field of diabetes.

Methods A literature review was conducted across multiple databases to identify published unit costs and cost data sources for resource items commonly used in health economic evaluations of antidiabetic therapies. The quality of unit cost reporting was assessed with regard to comprehensiveness of cost reporting and referencing as well as accessibility of cost sources from published cost-effectiveness analyses (CEA) of antidiabetic medications.

Results An overview of cost sources, including tariff and fee schedules as well as published estimates, was developed for France, Germany and Italy, covering primary and specialist outpatient care, emergency care, hospital treatment, pharmacy costs and lost productivity. Based on these sources, unit cost datasets were suggested for each country. The assessment of unit cost reporting showed that only $60 \%$ and $40 \%$ of CEAs reported unit costs and referenced them for all pharmacy items, respectively. Less than $20 \%$ of CEAs obtained all pharmacy costs from publicly available sources.

Conclusions This review provides a comprehensive account of available costs and cost sources in France, Germany and Italy to support health economists and increase transparency in health economic evaluations in diabetes.
\end{abstract}

Keywords Cost $\cdot$ Cost-effectiveness $\cdot$ Diabetes $\cdot$ France $\cdot$ Germany $\cdot$ Italy

JEL Classification D61 $\cdot$ I10

Electronic supplementary material The online version of this article (https://doi.org/10.1007/s10198-020-01229-1) contains supplementary material, which is available to authorized users.

\section{H. Sapin}

sapin_helene@lilly.com

1 Ossian Health Economics and Communications, Basel, Switzerland

2 Eli Lilly Finland, Helsinki, Finland

3 Eli Lilly and Company, Indianapolis, IN, USA

4 Lilly France, 24 Bd Vital Bouhot, CS 50004, 92521 Neuilly-sur-Seine Cedex, France

\section{Introduction}

Costs are key inputs into any health economic evaluation. Depending on the perspective and time horizon of the evaluation as well as available data, costs can be obtained from a variety of sources or calculated using several different approaches [1-5]. As discussed by Hoerger [6] in the context of cost-effectiveness modeling of diabetes, these costing approaches are neither standardized nor straightforward, so the choice of costs may be associated with uncertainty. Similar challenges have been observed, for example, in evaluations of cancer [7], hip fracture [8] and mental illness [9], as well as in health technology assessment (HTA) more broadly [10]. More standardized approaches to costing [11] and even standardized healthcare cost data [12] were suggested to increase transparency and comparability across studies, but articles outlining costing approaches often assume that a 
researcher has access to multiple sources of costing data, e.g. from institutional databases $[11,13]$. Such data may not be available to all researchers and difficult to assess or replicate by reviewers and readers. Instead, publicly available data may be used, which are usually free to access, use and verify, but these data can be difficult to find and are often distributed across multiple sources and platforms.

The present article aims to contribute to the use of publicly available cost sources, by providing an overview of available data sources for unit costs in France [14], Germany [15] and Italy [16], which were chosen as the largest healthcare markets in the European Union in the near future. The study builds on previous cost collection studies [17, 18], and supplements recent efforts, particularly in France and the United Kingdom (UK), to advance costing for healthcarerelated studies $[1,2,13,19,20]$.

In addition to providing an overview of cost data sources, the article presents suggested unit cost sets that can inform health economic analyses in these countries. While most unit costs are anticipated to be applicable to evaluations in different disease areas, the collection of unit costs was structured by requirements for health economic analyses primarily in type 2 diabetes (T2D), which is associated with substantial healthcare costs in all three countries under study. A recent study using French national health insurance data estimated that, in a population of 3 million people with diabetes in 2012, EUR 10 billion in 2012 (of EUR 19 billion in total expenditure) were attributable to diabetes care [21]. Another study, which also used national health insurance data, calculated annual costs of EUR 8.5 billion for patients with T2D in 2013, equivalent to 5\% of total health expenditure [22]. For Germany, a cost-of-illness study using statutory health insurance (SHI) data suggested that EUR 16.1 billion, equivalent to approximately $10 \%$ of statutory health insurance expenses in Germany, were spent each on the treatment of patients with T2D in 2009-2010 [23]. A costof-illness study for Italy estimated direct medical costs to the Servizio Sanitario Nazionale (SSN), the Italian National Health Service, in 2012 at EUR 9.6 billion, with an additional EUR 10.7 billion in indirect costs due to early retirement and absenteeism [24]. Important cost drivers in all three countries were diabetes-related complications, including renal, neuropathic and ophthalmologic complications [25-27], and adverse events, in particular hypoglycemia [28]. Due to the burden associated with T2D in these countries, health economic evaluations in the field of diabetes will continue to play an important role in healthcare resource allocation and decision-making, and the present cost collection contributes data to inform these analyses. As part of this study, the quality of pharmacy unit cost reporting in published cost-effectiveness analysis (CEA) of antidiabetic medications were also reviewed, to identify challenges and evidence gaps related to cost reporting.

\section{Methods}

\section{Searches to identify unit cost data sources}

Preliminary searches were developed based on the list of relevant resource items (Table 1) to test their performance and identify studies that could be used to refine the search strings, e.g. by providing additional search terms. Following development of the search strategy in this way, searches were performed in the electronic literature databases PubMed and Embase and in Google Scholar in line with the process detailed in Fig. 1. Final searches were based on the refined preliminary searches

Table 1 Resource use items of interest

\begin{tabular}{ll}
\hline Resource use category & Items of interest \\
\hline Primary outpatient care & Primary care physician/general practitioner (including practice visit, phone calls) \\
& Nurse (including practice visit, home visit or phone calls) \\
& Home or hospital visit (general) \\
& Diabetes educator or specialized staff \\
& Cardiologist; dentist; dermatologist; diabetologist/endocrinologist; dietician; nephrolo- \\
Specialist outpatient care & gist; neurologist; ophthalmologist; podiatrist; psychiatrist; psychotherapist \\
& Nurse/physician (as applicable) -includes visit at practice, phone calls and home visits \\
Diabetes training or education & Hospital admission (daytime or overnight stay) \\
Hospital and inpatient care & Intensive care unit \\
& Emergency department \\
Emergency medical care & Emergency medical services/ambulance transportation \\
Pharmacy & Medication \\
Intangible resource use & Consumables, including for self-monitoring of blood glucose \\
\hline
\end{tabular}




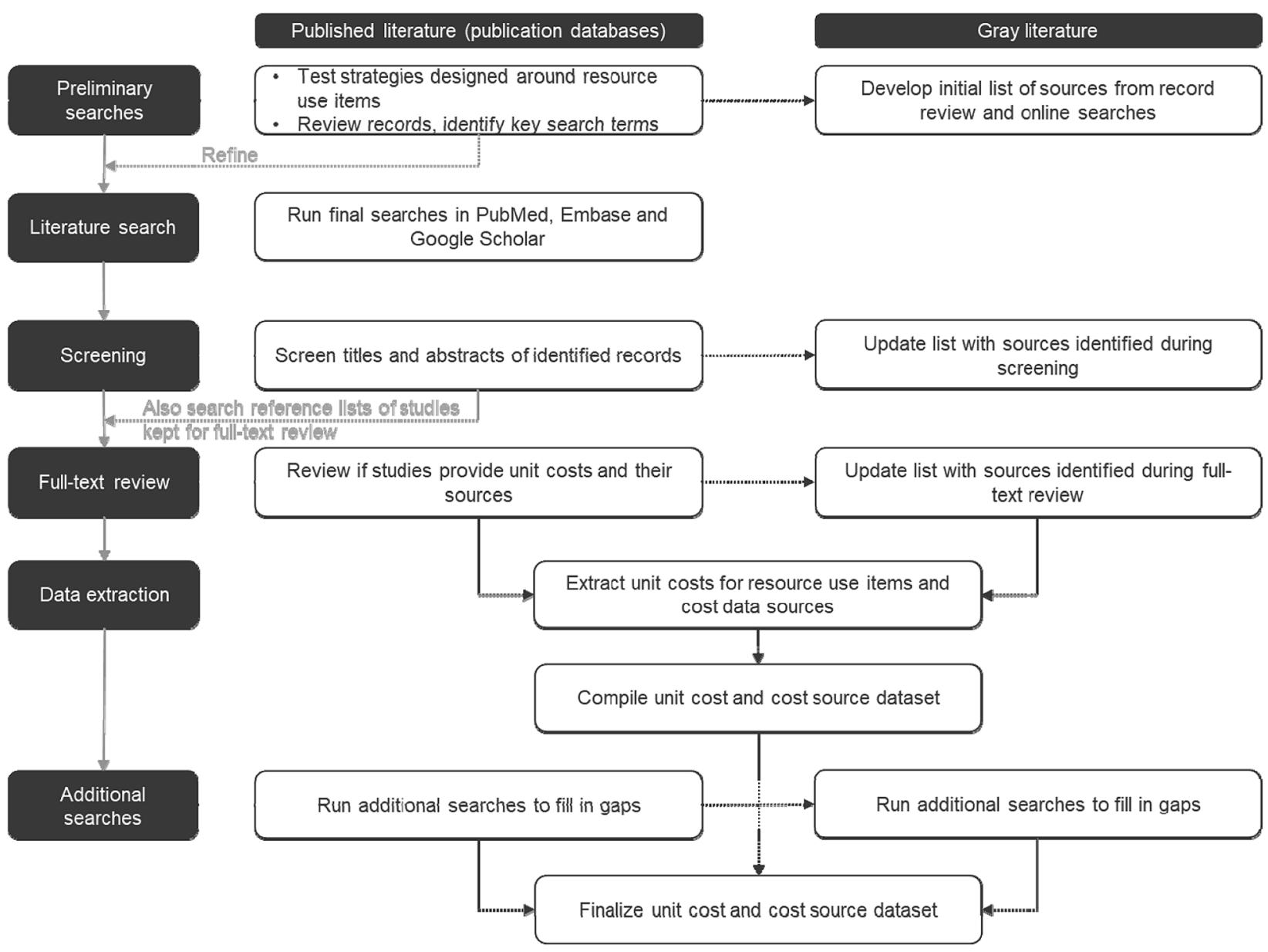

Fig. 1 Schematic diagram of the search process to identify unit costs and cost sources

and translated into database-specific vocabulary. For PubMed and Embase, searches designed to identify costs for office and diagnosis-related groups (DRGs)/tariffs were conducted without limiting the search to diabetes as many of these costs were not anticipated to vary substantially between patients with and without diabetes (see Online Resources 1-3 for PubMed search strategies). The same broad approach was not feasible for other resource use items as the number of retrieved records would have been beyond the scope of the present project.

Studies identified in unit cost data searches were eligible for inclusion if they reported unit costs for at least one of the resource items of interest in France, Germany or Italy. Searches targeted costs for populations with diabetes but populations with risk factors for or sequelae of diabetes (e.g. renal disease) were also considered. Studies were not eligible if they were not performed in at least one of the target settings, did not report unit costs or sources of unit costs, were a research protocol or abstract, or were published before 2012 (as costs reported by these studies were considered to be likely obsolete).

Study titles and abstracts were screened according to in- and exclusion criteria by a single researcher. Full-texts of studies retained in the first round of review were then reviewed in depth to determine final eligibility of a study. From eligible studies, unit costs and any information on cost data sources were extracted into a piloted Microsoft Excel workbook to compile a dataset for unit costs and cost sources. Years of reported costs were also extracted to assess how recent costs were at the time of publication and time of search. Additional searches to fill any data gaps were planned but not ultimately required. These data, which were obtained from the literature, were complemented with manual searches of data from HTA, pricing and reimbursement authorities. Searches were last run on 16 October 2018. As only descriptive cost data were extracted from studies, bias assessment was not required. 


\section{Searches to identify health economic evaluations of antidiabetic medication}

A separate search was conducted to obtain CEAs to assess the quality of unit cost reporting. Studies were eligible if they reported a CEA (which, for the purposes of the present study, also included cost-utility and cost-benefit analyses) of antidiabetic mediation in patients with diabetes. Studies were considered if they were conducted in any of the three target countries or in Spain or the UK with the latter two countries included to increase the pool of eligible studies while covering the major European healthcare markets. Research protocols and abstracts were excluded as were studies published before 2012 and studies not investigating antidiabetic medications but medical devices (e.g. insulin pumps).

Both PubMed and Embase were searched, with development of search strategies and screening following the procedure outlined above for pharmacy unit cost data (see Online Resource 4 for the PubMed search strategy). Pharmacy costs, specifically the acquisition costs associated with medications, were chosen (as opposed to complication costs, for example) as they could be expected to be included in all analyses, thereby increasing comparability. Three quality indicators were developed and extracted for pharmacy costs from each included CEA, independently by two researchers. First, it was assessed if unit cost values used were reported for all antidiabetic medications under study. Studies were classified as "All", "In part" or "None" if they reported a unit cost value for all, some or no antidiabetic medication, respectively. Second, it was assessed if used unit costs were referenced so that they could be checked against their source. Studies were again classified as "All", "In part" or "None" if they provided a clear reference, e.g. a paper or unified resource locator with all the required details to uniquely identify the cost in a database, for all, only some or none of the unit cost values, respectively. Third, it was assessed if cost sources were freely accessible or required a subscription or registration. This criterion was deemed important as transparency relies on accessibility of sources without undue costs or administrative burden. Studies were classified as "All", "In part" or "None/no references" if all, some or no cost source was freely accessible (with studies providing no cost source references grouped as "None/no references" for this indicator). If a study reported analyses for multiple countries, each country-specific analysis was considered separately.

\section{Data management and presentation}

Cost data were presented in country-specific tables, one each for sources of cost data and for suggested unit costs for the items of interest. The quality assessment of unit cost reporting in CEAs was summarized in descriptive statistics. All data were stored in Microsoft Excel workbooks and, where applicable, analyzed using R version 3.5.1 [29].

\section{Results}

\section{Overview of search results and study selection}

The search of literature databases for studies reporting unit costs and cost sources for France, Germany and Italy yielded 2944 hits, of which 2065 were unique articles that were titleand-abstract-screened for full-text review (Fig. 2). All relevant inclusion/exclusion criteria were applied to each article, with the most frequently applied exclusion criteria being that an article did not report unit costs and/or health economic evaluations or was not in diabetes or related diseases. Ten studies were added from manual searches of HTA reports and databases.

With regard to searches for health economic evaluations, 7122 hits, of which 5365 were unique articles, were retrieved from databases (Fig. 2). An additional five studies were obtained from manual searches of HTA reports and databases.

Search results were combined and duplicates removed, yielding 180 articles for full-text review. Criteria for inclusion as a cost-reporting study or health economic evaluation were applied, and each included study was classified as reporting unit costs (or cost sources) and/or a health economic evaluation. In total, 57 studies were included, of which 38 reported unit costs or cost sources and 38 were health economic evaluations.

\section{Results for unit costs and cost data sources}

Of publications reporting unit costs or cost sources, fewer were identified for France $(n=9)$ [30-37] than for Germany $(n=15)$ [23, 38-50] or Italy $(n=15)$ [51-64], with one study reporting data for all three countries [65]. A range of cost sources and unit costs could be obtained from these studies for the resource use items of interest (Table 1).

\section{Cost sources for France}

France has a heavily centralized healthcare system centered on SHI (Assurance Maladie), which is part of the French Social Security System. The SHI has different schemes that together cover up to $98 \%$ of the population $[14,66,67]$.

For consultations with primary care and specialist physicians, the SHI publishes "conventional tariffs" for both mainland France and the French overseas territories (Table 2). These tariffs are available for a range of settings (e.g. office versus teleconsultation versus home visit at different times 


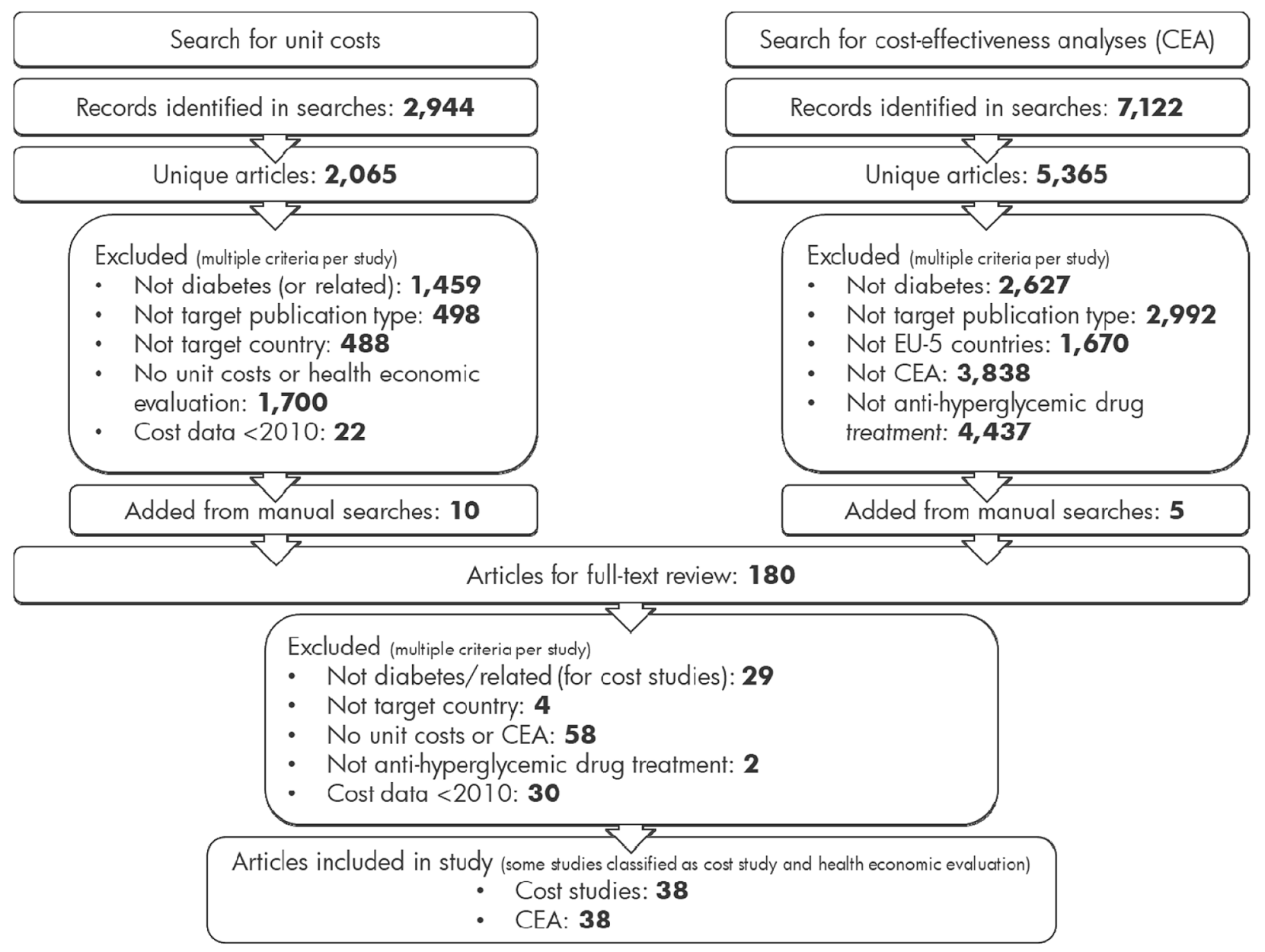

Fig. 2 Flowchart for database searches and study selection

of day/night; regular office hours versus public holidays) and can be used to cost consultations with and visits to physicians. Depending on the type of (procedural) data available to the analyst, e.g., in the context of an observational study, detailed procedural tariffs can be obtained from another SHI source, the Classification Commune des Actes Médicaux (CCAM). The CCAM is based on the French nomenclature for medical acts (Nomenclature Générale des Actes Professionnels, NGAP) and contains consultations and clinical procedures, specified by keywords, procedure code or clinical field and based on regularly updated nomenclature, in addition to monetary values for each procedure.

Responsibility for emergency medical services (EMS), in the form of either land or air rescue (Structure Mobile d'Urgence et de Reanimation, SMUR), rests with hospitals as part of regional emergency care infrastructures. SMUR services are frequently provided by university hospitals (Centre Hospitalier Universitaire, CHU) and SMUR tariffs can be obtained from the websites of various CHUs. For planned patient transports, with varying levels of patient supported required, SHI tariffs are available. Of note, the cost database Base d'Angers provides actual SMUR cost data from its participating institutions in France. This database could be used to complement the tariffs outlined in the sources above.

Costs associated with emergency department (ED) treatment can be sourced from national unit cost reference data (Référentiel de Coût des Unités d'Oeuvres, RTC). The RTC provides unit costs calculated from participating institutions for a wide range of clinical, technical and logistical services related to healthcare, including costs associated with emergency medical treatment (e.g. code 932112-Admission and treatment of medical emergencies). The data are available online and freely accessible, with the latest data from 2016. For hospitalization, including stays in intensive care units (ICU), tariffs for the French DRGs, the Groupes Homogènes de Séjours, are freely available online from the Technical Agency for Information on Hospital Stays 


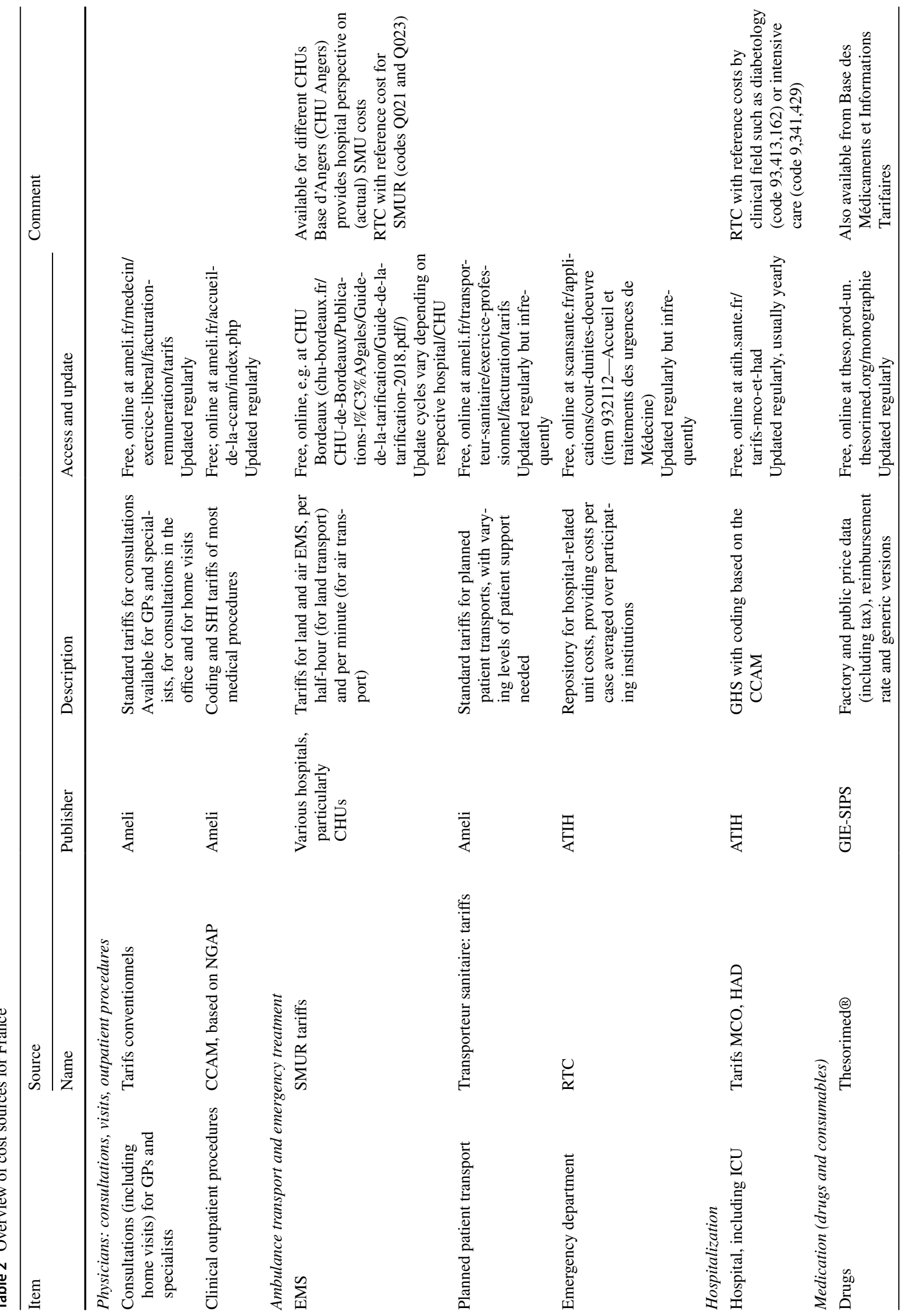




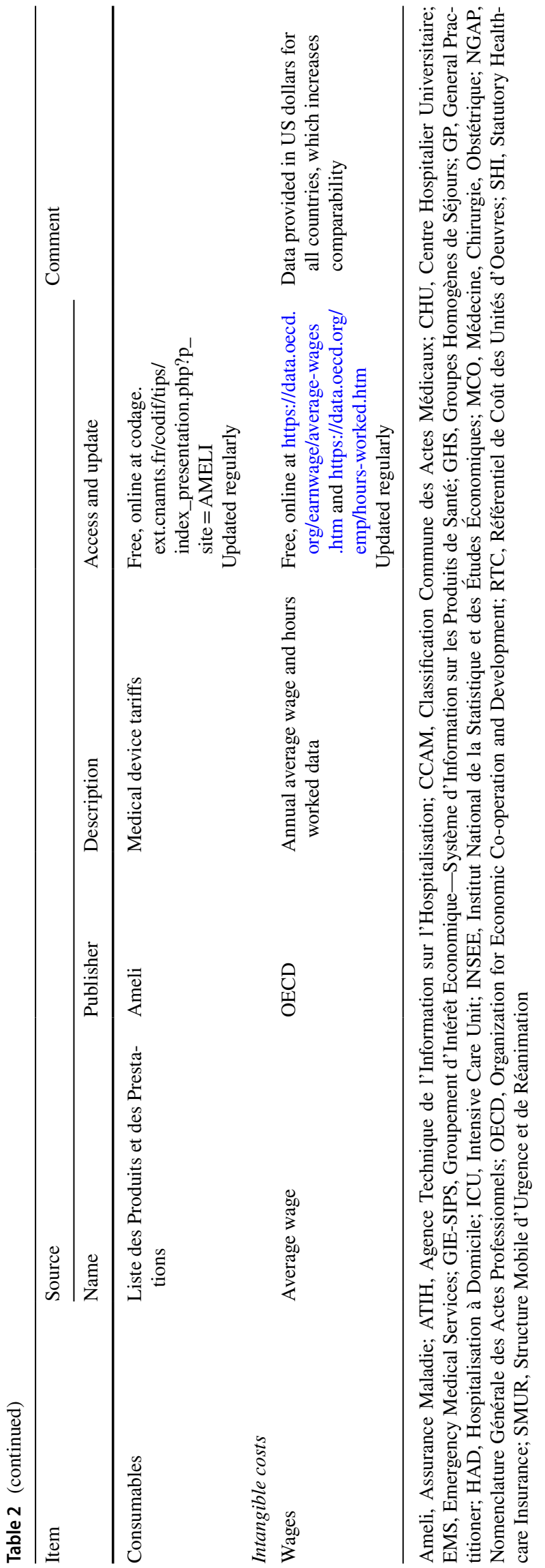

(Agence Technique de l'Information sur l'Hospitalisation). Again, actual costs from participating institutions are also available from the RTC.

Pharmacy and consumable costs in France are also freely available online. These costs can be accessed using a variety of different interfaces. For pharmacy costs, Thesorimed ${ }^{\circledR}$ provides a modern user interface and information on a medication's reimbursement status, costs (including and excluding taxes), generics and equivalents, and reimbursement decisions. For medical devices, costs can be accessed from the list of products and benefits (Liste des Produits et des Prestations).

Regarding intangible resource use, measured as time lost and valued using wages, this can be obtained from the Organization for Economic Co-operation and Development (OECD), which may be preferred if wage data are required for multiple countries to ensure consistency and comparability of calculations. Similar data are provided in the official wage and labor statistics published by the National Institute of Statistics and Economic Studies (Institut National de la Statistique et des Études, INSEE). The INSEE provides longitudinal gross and net wage data, which are freely accessible online.

Based on the cost sources identified for France, a suggested unit cost dataset (Online Resource 6) was developed for the resource items of interest. This dataset, which mirrors and updates previous work for France [36], can be used in its current form or as a starting point for a dedicated cost collection.

\section{Cost sources for Germany}

The German healthcare system is centered on statutory and private healthcare insurance (PHI) [15]. Statutory insurance is corporatist and mostly self-regulated on behalf of the government in negotiations by sickness funds (payers) and physician, dentist and hospital associations (providers). A distinctive feature of the German healthcare system is the existence of full-cover PHIs. While PHIs use the same DRG schedule as statutory sickness funds, they differ in fee schedules for physicians. Cost data for both SHI and PHI are presented although the focus is on SHI, which covers approximately $80 \%$ of the population [15].

Cost data for consultations with primary care or specialist physicians (in the office, at home or via phone) are available from the Uniform Value Scale (Einheitlicher Bewertungsmassstab, EBM) from an SHI perspective (Table 3). The EBM is a database of procedures and services that physicians may charge SHI. The data are available online and freely accessible. Equivalent data for the PHI perspective can be sourced from fee schedules for physicians (Gebührenordnung für Ärzte, GOÄ) and dentists (Gebührenordnung für Zahnärzte, GOZ), respectively. Both are freely 


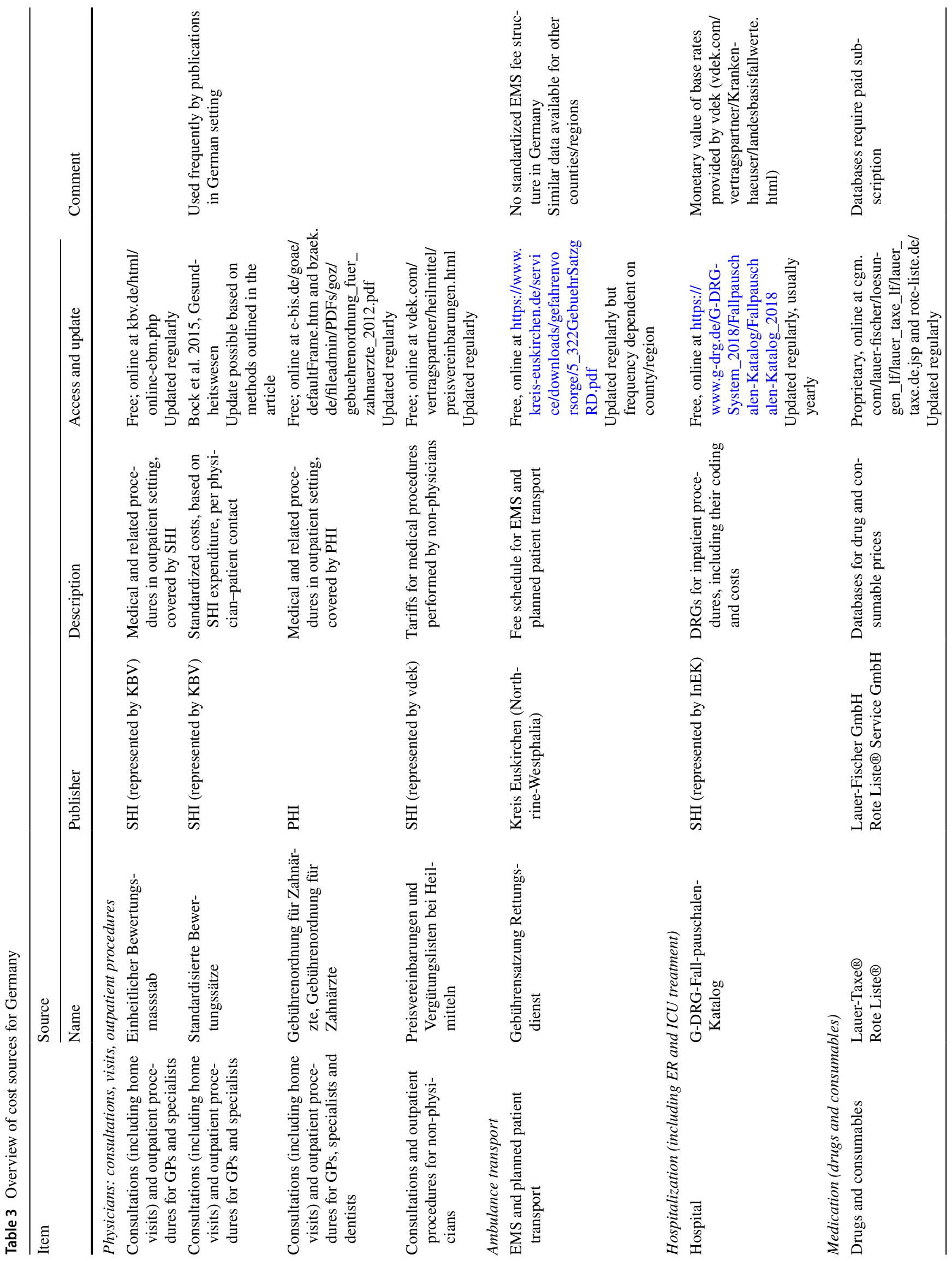


available online. In addition to these databases, a frequently referenced source of unit costs, including for visits to physicians, is the study by Bock et al. [39]. In this study, the authors calculated "valuation rates" for physician-patient contacts based on overall budgets paid to physicians by sickness funds and contact data, while also including PHI data. These valuation rates are used frequently in German health economic evaluations covering a range of disease areas due to their convenience and granularity [48, 68, 69]. Similar data, providing average remuneration per case, are provided by the National Association of Statutory Health Insurance Physicians (Kassenärztliche Bundesvereiningung) in their yearly report. For consultations and services provided by non-medical personnel such as podologists, tariff lists are available online from sickness fund associations (e.g. Verband der Ersatzkassen).

Costs of ambulance transportation are regulated at the local and regional level, so no nationwide applicable fees exist. Examples identified during the review include recent fee schedules for Euskirchen county (in North Rhine-Westphalia), but schedules covering other municipalities and regions are also available. Emergency department treatment in Germany is performed in hospitals and, therefore, covered by the G-DRG system, as are inpatient stays and ICU treatment. Both the G-DRG system and a list of monetary base rate values are freely accessible online.

Unlike in France and Italy, pharmacy cost data are not freely accessible in Germany. Instead, a paid subscription is required to access databases such as the Lauer-Taxe ${ }^{\circledR}$ or the Rote Liste ${ }^{\circledR}$. Drug prices from 1 year after market introduction can be approximated using reimbursement prices from price-setting negotiations. However, these prices do not reflect prices during the first year after market introduction, sickness fund-specific rebates and other changes to prices. Data on wages and hours worked can be sourced from the OECD but are also available from the Federal Statistical Office (Destatis).

Based on the cost sources identified for Germany, a suggested unit cost dataset was developed for the resource items of interest (Online Resource 7).

\section{Cost sources for Italy}

The Italian healthcare system is highly decentralized. Within the SSN, implementation and delivery of healthcare rests with the 21 regions and provinces. Most costs are, therefore, available from different regions. In the cost dataset compiled for Italy, costs were presented for the Bolzano, EmiliaRomagna, Umbria and Apulia provinces/regions to obtain a broad geographic spread across the country.

Costs of consultations, including primary and specialist care in the office and for home visits, can be sourced from regional tariffs (Nomenclatore tariffario regionale) (Table 4). 


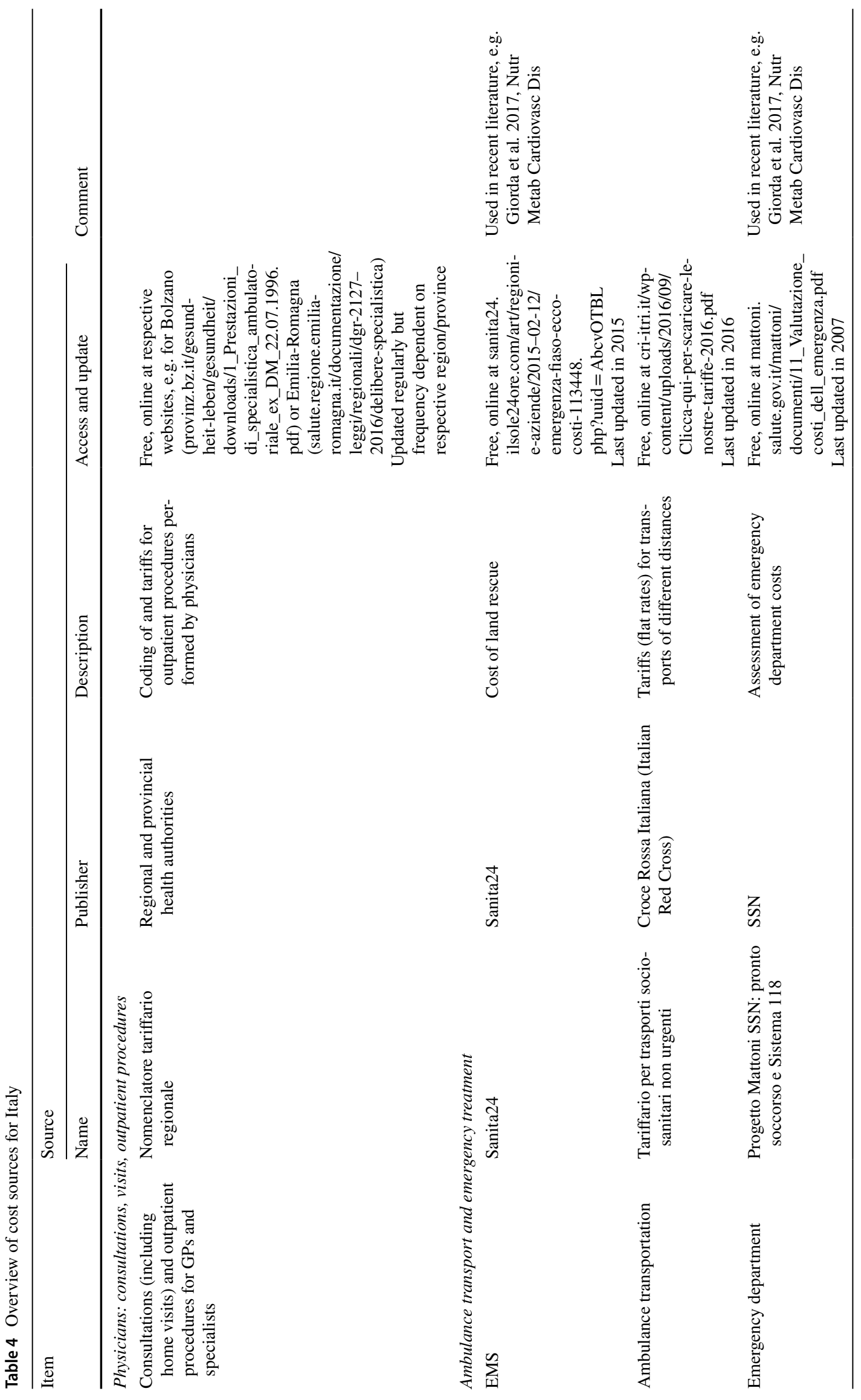




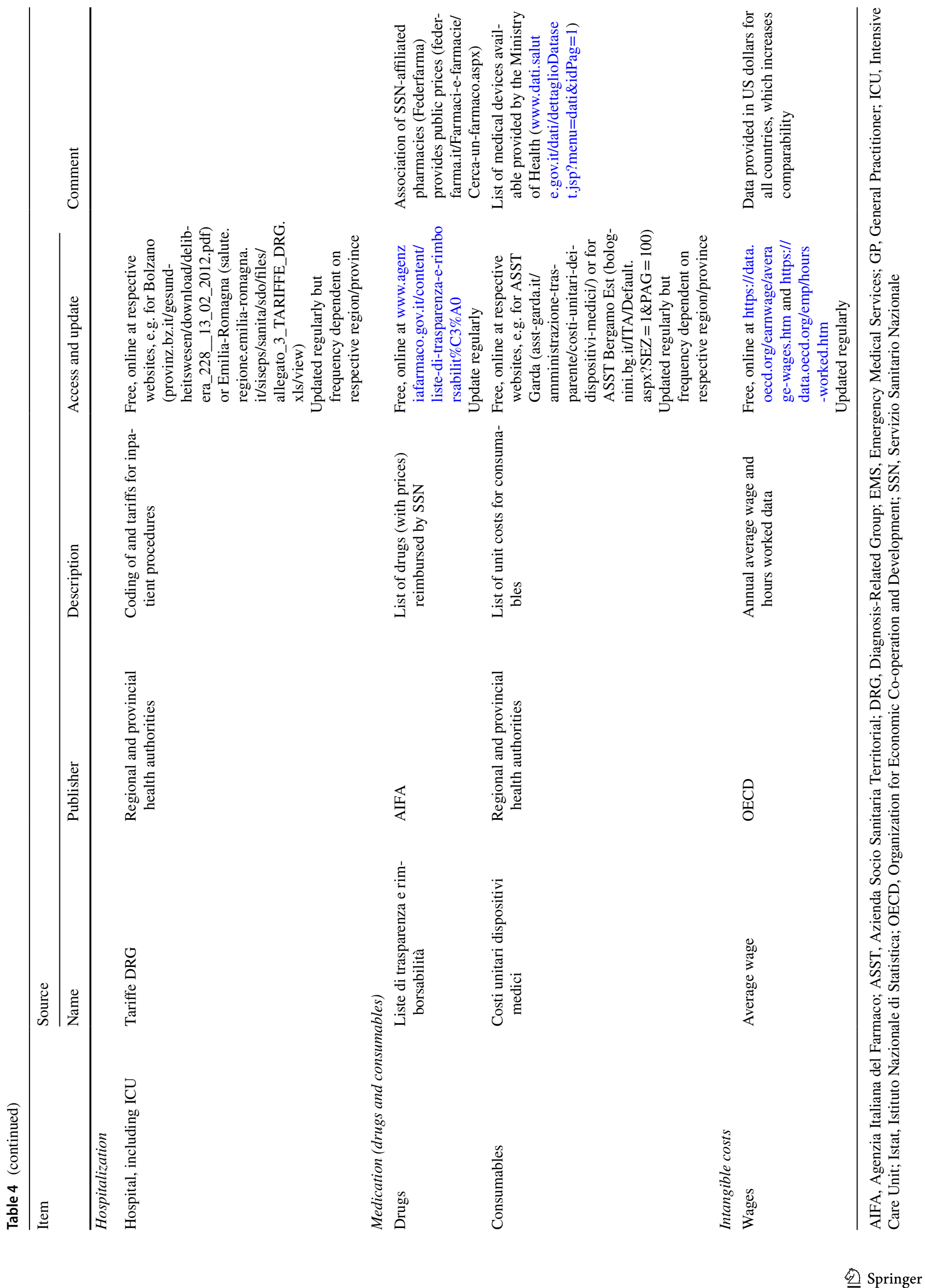


Tariff lists are generally freely available online and updated regularly although update frequency differs between regions.

By comparison, cost data for EMS and planned patient transports as well as ED treatment costs are more difficult to obtain. For EMS, a commonly used reference in the literature for Italy is based on a costing study covering the Basilicata, Emilia-Romagna, Lazio and Lombardy regions, which is used in the recent literature [58]. For planned patient transports, the Italian Red Cross provides flat-rate tariffs per transport that differ by vehicle type, staffing and number of journey and are supplemented with mileage allowances. For ED treatment, unit costs published in 2007 by the Progetto Mattoni SSN are still in use despite their age [58].

Regional DRG tariffs are available for inpatient treatment, including ICU treatment. These are freely accessible online, with update frequency and convenience of access differing between regions. Current pharmacy costs are also freely available online, from the Italian Medicines Agency (Agenzia Italiana del Farmaco), which provides an SSN perspective, while the Italian Federation of Pharmacies provides a database of public prices. Consumables covered by SSN were listed by the Ministry of Health, while corresponding cost data were again provided by regional and local health authorities. Data on wages and hours worked, based on national labor agreements, are available from the National Statistics Institute (IStat) and the OECD.

Based on the cost sources identified for Italy, a suggested unit cost dataset was developed for the resource items of interest (Online Resource 8).

\section{Quality of pharmacy cost reporting in CEAs}

Overall, 38 studies reporting health economic analysis of antidiabetic medications were included, with one study reporting evaluations for three countries of interest [30, $51,70-105]$. Of the 40 evaluations, most were for the UK $(n=23)$, followed by Spain $(n=9)$ and Italy $(n=4)$, with two each from France and Germany. With regard to reporting pharmacy unit costs used, $60 \%(n=24)$ of evaluations reported all, while $7.5 \%(n=3)$ reported only some and $32.5 \%(n=13)$ reported none of the unit costs for included antidiabetic medications. All costs were referenced clearly by $40 \%(n=16)$, whereas $30 \%(n=12)$ provided references for only some or none of the costs. In $17.5 \%(n=7)$ of evaluations, all pharmacy costs were obtained from freely accessible sources while some non-freely accessible sources were used in $20 \%(n=8)$ of evaluations, with the remainder either not referencing any pharmacy cost or using costs that were not freely accessible. Overall, only two evaluations (5\%) reported and referenced all pharmacy costs and used freely accessible sources, while nine (22.5\%) did neither report nor reference any pharmacy unit costs (Fig. 3).

\section{Discussion}

The present review was designed to provide a comprehensive, practical overview of cost data sources and unit costs suitable for health economic evaluations in the field of diabetes, for France, Germany and Italy. Both sources and costs were obtained from published studies and the gray literature, and included tariff and fee schedules for physician consultations (in the office and at home), out- and inpatient procedures, EMS and ED treatment as well as pharmacy prices and valuations of lost productivity based on wages.

Some differences between countries regarding availability, ease-of-access and comprehensiveness of cost sources were observed. In a centralized healthcare system such as in France, SHI and nationwide data sources were available for almost all resource items of interest. While these sources were generally found to be current and updated regularly (with many available in modern user interfaces), they were complex to use, often requiring an intimate knowledge of the French healthcare system [13, 19, 66]. In addition, recent transitions between classification systems and the number of different data sources available further increased the complexity of obtaining data and targeting the most relevant information. Of note, several large-scale clinical and cost databases were available in France, in particular the nationwide Système National d'Information Interrégimes de l'Assurance Maladie (SNIIRAM) which will be expanded to national health data system over the next years $[66,67]$. The demographic, health and cost data provided by SNIIRAM and its subset, the Echantillon Généraliste de Bénéficiaires (EGB), were frequently used in the healthcare literature for France [21, 35, 36]. These sources were considered to be of high quality and to likely represent the best data choice for real-world studies of costs, but were not necessarily suitable for health economic evaluations, particularly those involving modelling. Use of the SNIIRAM and EGB databases is complex and requires prior approval by the steering committee as data are not publicly available, thereby limiting transparency. Published SNIIRAM cost estimates, in turn, were usually population specific and not suitable for use as unit costs although aggregate SNIIRAM costs may inform, for example, the costing of diabetes-related complications (which is beyond the scope of the present study).

For Germany, which has a corporatist healthcare system, nationwide tariff and fee schedules were also identified, many of them available online and in modern user interfaces. A distinctive feature of the healthcare system in Germany was the important role played by PHI, so data could be sourced from different sources depending on the perspective of interest. An example was the costing of 


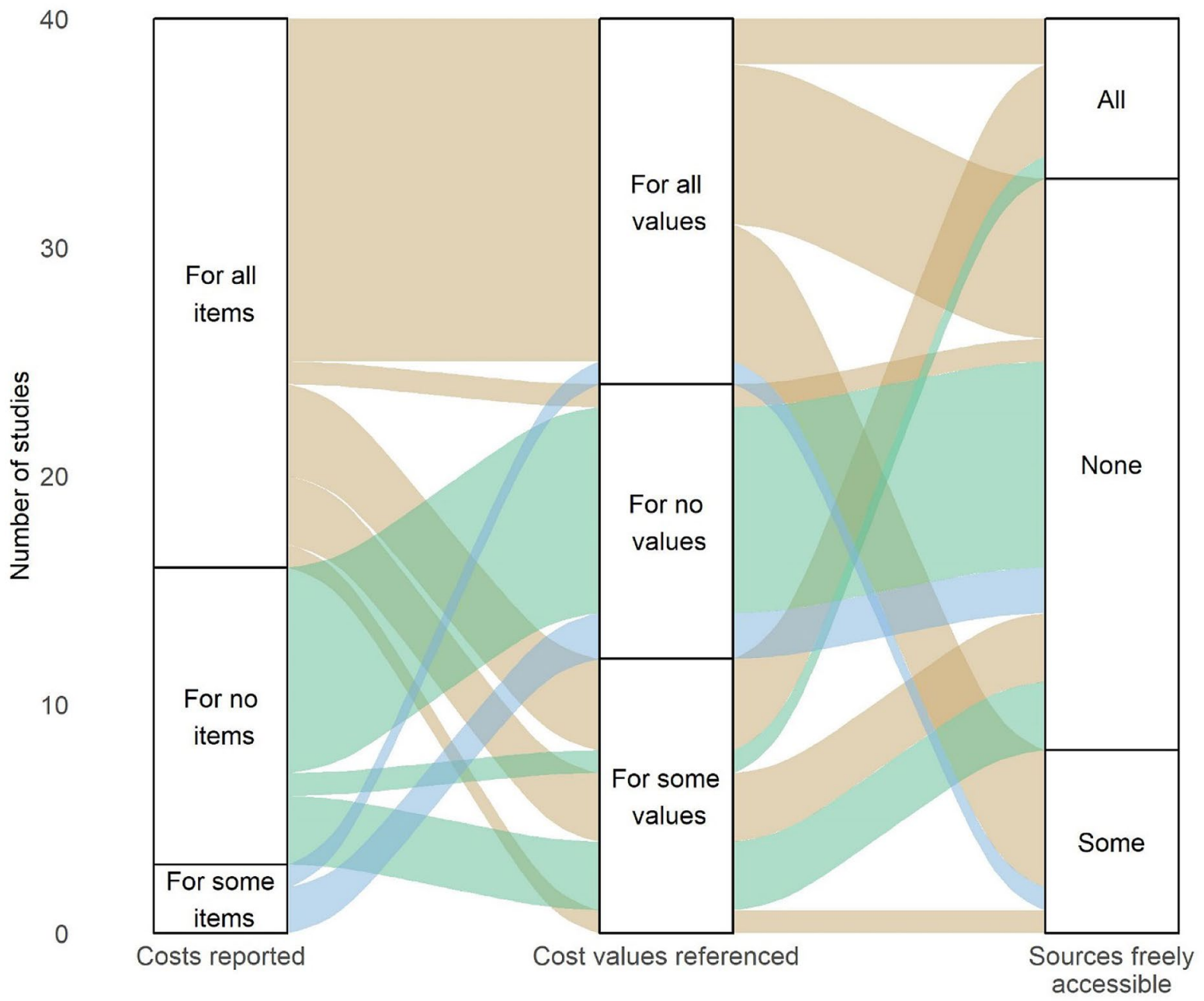

Fig. 3 Quality of pharmacy unit cost reporting. Note: costs reported and referenced refers to reporting of pharmacy unit costs

physician consultations and outpatient procedures, which would be performed using the EBM from the SHI perspective and the GOÄ/GOZ from the PHI perspective. Unlike France and Italy, however, drug prices were not freely available for the German setting as the two most popular databases required paid subscriptions. Prices could be approximated using publicly available data from price setting negotiations, but these would not account for rebates and not necessarily reflect current prices.

In contrast, multiple sources for each resource use item were available in the decentralized Italian healthcare system. While item coding was usually consistent across healthcare regions and unit costs were often similar, researchers would still be required to decide on the healthcare region to which obtain data from. As became evident during the review, regions differ in the quality and usability of their healthcare cost data available online, which may influence the choice of data. With the ARNO Observatory and Associazione Medici Diabetologi Annals, large-scale, diabetes-specific databases of clinical outcomes and costs for patients were also available $[52,61,106]$. Similar to the SNIIRAM and EGB databases, however, their use would be very complex and require prior approval while published aggregate costs from these sources would not usually be suitable as unit costs.

Common to all three countries were differences in data availability and quality between items. Tariff and fee schedules covering activities of physicians and inpatient procedures were straightforward to identify and updated regularly. In contrast, data covering non-physician medical staff, e.g. nurses, or EMS were harder to obtain and generally of poorer quality. Particularly in the case of EMS, this likely reflected the absence of central planning or reimbursement, for which responsibility often laid with private or non-governmental organizations.

Despite its comprehensiveness, the present review was not without limitations. The review did not consider different costing approaches, many of which have been discussed in the literature, particularly for France [1-4, 
11]. Such a methodologic discussion may be relevant for some studies, including those where bottom-up costing approaches may be feasible. In contrast, the present study was focused on providing a practical overview of different cost sources, especially targeting health economics research where costs need to be obtained from an external source, e.g. in case of long-term modeling. A frequent challenge in this context is the use of tariffs and fee schedules such as the German EBM or DRG in the absence of detailed procedural data for a patient population. In this case, assumptions have to be made regarding the likely procedures that an average patient may have undergone, e.g. during a consultation with a diabetologist, as was done in the present study for developing suggested unit cost datasets (Online Resources 6-8). While assumptions introduce uncertainty, particularly with regard to overall costs or budget impact, their impact might be smaller for comparative outcomes such as cost-effectiveness as incremental differences would not be affected as long as the same cost set was used in all arms of the analysis. An additional limitation was the restriction of literature searches to studies reporting costs or cost sources in the context of diabetes. This restriction, which was applied to keep searches practicable, may have implied that potential costs or cost sources were missed. However, as searches covered several years of published studies in both English and the local language and were supplemented with searches of reference lists and the gray literature, the risk of missing costs or sources was considered small.

The overview of cost sources and suggested unit cost datasets was designed not only to provide researchers with a starting point for their analyses and cost collections but also to increase the transparency and accessibility of costs in health economic evaluations $[6,11,20]$. As part of the present study, the quality of unit cost reporting of pharmacy costs in CEAs of antidiabetic medications in the five largest European healthcare markets was assessed. Few studies were found to report and reference costs in full while using cost sources that were freely accessible. These findings did not imply that authors deliberately tried to obfuscate data as, instead, journal restrictions on the number of tables or word limits are much more likely to be responsible for the lack of comprehensive reporting. However, the use of nonstandardized costs and difficulties in assessing their origin limit the transparency and transferability of health economic evaluations, particularly in the context of HTA [107, 108]. The value of a more standardized approach to HTA methods was discussed previously [109] and likely extends to HTA input data, including costs [110]. An overview of available unit costs and cost sources, in addition to their transparent reporting, can provide a first step towards more transparent HTA and health economic evaluations.

\section{Conclusion}

This review provided cost data sources and unit costs for use in health economic evaluations in France, Germany and Italy. Differences between countries were observed in ease-of-access for and complexity of cost databases, which partly reflected the structure of the respective health care system. Similarly, differences were observed between resource use items, with more cost data available for in- and outpatient procedures than for EMS or activities performed by non-physician medical staff. The resources highlighted in this study could be used to support health economists in obtaining country-specific cost data required for modeling, particularly in the field of diabetes. Cost collection studies of this type can contribute to increased transparency and standardization of cost data used in health economics and HTA.

Open Access This article is licensed under a Creative Commons Attribution 4.0 International License, which permits use, sharing, adaptation, distribution and reproduction in any medium or format, as long as you give appropriate credit to the original author(s) and the source, provide a link to the Creative Commons licence, and indicate if changes were made. The images or other third party material in this article are included in the article's Creative Commons licence, unless indicated otherwise in a credit line to the material. If material is not included in the article's Creative Commons licence and your intended use is not permitted by statutory regulation or exceeds the permitted use, you will need to obtain permission directly from the copyright holder. To view a copy of this licence, visit http://creativecommons.org/licenses/by/4.0/.

\section{References}

1. Guerre P, Hayes N, Bertaux AC, French Costing Group. Hospital costs estimation by micro and gross-costing approaches. Rev. Epidemiol. Sante Publique 66(Suppl. 2), S65-S72 (2018)

2. Culyer A. Cost, context, and decisions in health economics and health technology assessment. Int. J. Technol. Assess. Health Care 34(5), 434-441 (2018) [epub ahead of print]

3. Morelle M, Plantier M, Dervaux B, Pagès A, Deniès F, Havet N, Perrier L; French Costing Group. [Methods for the analysis and treatment of cost data by micro- and gross-costing approaches]. Rev. Epidemiol. Sante Publique 66(Suppl. 2), S101-S118 (2018)

4. Barnett, P.G.: An improved set of standards for finding cost for cost-effectiveness analysis. Med. Care 47(7 Suppl. 1), S82-S88 (2009)

5. Briggs, A.D.M., Scarborough, P., Wolstenholme, J.: Estimating comparable English healthcare costs for multiple diseases and unrelated future costs for use in health and public health economic modelling. PLoS ONE 13(5), e0197257 (2018). https ://doi.org/10.1371/journal.pone.0197257

6. Hoerger, T.J.: Using costs in cost-effectiveness models for chronic diseases: lessons from diabetes. Med. Care 47(7 Suppl. 1), S21-S27 (2009)

7. Yabroff, K.R., Borowski, L., Lipscomb, J.: Economic studies in colorectal cancer: challenges in measuring and comparing costs. J. Natl. Cancer Inst. Monogr. 2013(46), 62-78 (2013) 
8. Leal, J., Manetti, S., Buchanan, J.: The impact of hospital costing methods on cost-effectiveness analysis: a case study. Pharmacoeconomics 36(10), 1263-1272 (2018)

9. Hu, T.W.: Perspectives: an international review of the national cost estimates of mental illness, 1990-2003. J. Ment. Health Policy Econ. 9(1), 3-13 (2006)

10. Mayer, S., Kiss, N., Łaszewska, A., Simon, J.: Costing evidence for health care decision-making in Austria: A systematic review. PLoS ONE 12(8), e0183116 (2017)

11. Lipscomb, J., Barnett, P.G., Brown, M.L., Lawrence, W., Yabroff, K.R.: Advancing the science of health care costing. Med. Care 47(7 Suppl. 1), S120-S126 (2009)

12. Visscher, S.L., Naessens, J.M., Yawn, B.P., Reinalda, M.S., Anderson, S.S., Borah, B.J.: Developing a standardized healthcare cost data warehouse. BMC Health Serv. Res. 17(1), 396 (2017)

13. Mercier G, Costa N, Dutot C, Riche VP; French Costing Group. Data sources, the data used, and the modality for collection. Rev. Epidemiol. Sante Publique 66 (Suppl. 1), S73-S91 (2018)

14. Chevreul K, Durand-Zaleski I, Bahrami SB, HernándezQuevedo C, Mladovsky P. France: health system review. Health Syst Transit. 12(6), 1-291, xxi-xxii (2010)

15. Busse R, Blümel M. Germany: health system review. Health Syst Transit 16(2), 1-296, xxi (2014)

16. Ferre, F., de Belvis, A.G., Valerio, L., Longhi, S., Lazzari, A., Fattore, G., Ricciardi, W., Maresso, A.: Italy: health system review. Health Syst Transit 16(4), 1-168 (2014)

17. Ray, J.A., Valentine, W.J., Secnik, K., Oglesby, A.K., Cordony, A., Gordois, A., Davey, P., Palmer, A.J.: Review of the cost of diabetes complications in Australia, Canada, France, Germany, Italy and Spain. Curr. Med. Res. Opin 21(10), 1617-1629 (2005)

18. Lund, J.L., Yabroff, K.R., Ibuka, Y., Russell, L.B., Barnett, P.G., Lipscomb, J., Lawrence, W.F., Brown, M.L.: Inventory of data sources for estimating health care costs in the United States. Med. Care 47(7 Suppl. 1), S127-S142 (2009)

19. Margier J, Baffert S, Le Corroller-Soriano AG; French Costing Group. Standard or specific unit costs: which criteria for choosing an economic evaluation of health strategies in multicentric studies? Rev. Epidemiol. Sante Publique 66(Suppl. 2), S93-S99 (2018)

20. Franklin M, Lomas J, Walker S, Young T. An educational review about using cost data for the purpose of cost-effectiveness analysis. Pharmacoeconomics (2019) [epub ahead of print]

21. de Lagasnerie, G., Aguadé, A.S., Denis, P., Fagot-Campagna, A., Gastaldi-Menager, C.: The economic burden of diabetes to French national health insurance: a new cost-of-illness method based on a combined medicalized and incremental approach. Eur. J. Health Econ. 19(2), 189-201 (2018)

22. Charbonnel, B., Simon, D., Dallongeville, J., Bureau, I., Dejager, S., Levy-Bachelot, L., Gourmelen, J., Detournay, B.: Direct medical costs of type 2 diabetes in France: an insurance claims database analysis. Pharmacoecon. Open 2(2), 209-219 (2018)

23. Jacobs, E., Hoyer, A., Brinks, R., Icks, A., Kuß, O., Rathmann, W.: Healthcare costs of type 2 diabetes in Germany. Diabet. Med. 34(6), 855-861 (2017)

24. Marcellusi, A., Viti, R., Mecozzi, A., Mennini, F.S.: The direct and indirect cost of diabetes in Italy: a prevalence probabilistic approach. Eur. J. Health Econ. 17(2), 139-147 (2016)

25. Turchetti G, Bellelli S, Amato M, Bianchi S, Conti P, Cupisti A, Panichi V, Rosati A, Pizzarelli F; On Behalf of the Tuscany CKD Study Group. The social cost of chronic kidney disease in Italy. Eur. J. Health Econ. 18(7), 847-858 (2017)

26. Couillerot-Peyrondet AL, Sambuc C, Sainsaulieu Y, Couchoud $\mathrm{C}$, Bongiovanni-Delarozière I.Turchetti $\mathrm{G}$, Bellelli $\mathrm{S}$, Amato M, Bianchi S, Conti P, Cupisti A comprehensive approach to assess , Panichi V, Rosati A, Pizzarelli F; On Behalf of the costs of renal replacement therapy for end-stage renalTuscany CKD Study Group. The social cost of chronic kidney disease in France: the importance of age, diabetes status, and clinical events.Italy. Eur. J. Health Econ. 18(4), 459-4697), 847-858 (2017)

27. Kähm, K., Laxy, M., Schneider, U., Rogowski, W.H., Lhachimi, S.K., Holle, R.: Health care costs associated with incident complications in patients with type 2 diabetes in Germany. Diabetes Care 41(59), 971-978 (2018)

28. Veronese G, Marchesini G, Forlani G, Saragoni S, Degli Esposti L, Centis E, Fabbri A; Italian Society of Emergency Medicine (SIMEU). Costs associated with emergency care and hospitalization for severe hypoglycemia. Nutr. Metab. Cardiovasc. Dis. 26(4), 345-351 (2016)

29. R Core Team. R: a language and environment for statistical computing. R Foundation for Statistical Computing. https://www.Rproject.org/ (2018). Accessed 13 February 2019

30. Basson M, Ntais D, Ayyub R, Wright D, Lowin J, Chartier F, Roze S, Norrbacka K. The cost-effectiveness of dulaglutide $1.5 \mathrm{mg}$ versus exenatide qw for the treatment of patients with type 2 diabetes mellitus in France. Diabetes Ther. 9(1), 13-25 (2018)

31. Chevalier, J., Delaitre, O., Hammès, F., de Pouvourville, G.: Cost-effectiveness of dabigatran versus vitamin $\mathrm{K}$ antagonists for the prevention of stroke in patients with atrial fibrillation: a French payer perspective. Arch. Cardiovasc. Dis. 107(6-7), 381-390 (2014)

32. Detournay B, Bureau I, Gourmelen J. The cost of insulin therapy in patients with type 2 diabetes, in France. Méd. Malad. Métabol. 9(Suppl. 3), 3S30-3S33 (2015)

33. François M, Hanslik T, Dervaux B5, Le Strat Y, Souty C, Vaux S, Maugat S, Rondet C, Sarazin M, Heym B, Coignard B, Rossignol $\mathrm{L}$. The economic burden of urinary tract infections in women visiting general practices in France: a cross-sectional survey. BMC Health Serv. Res. 16(a), 365 (2016)

34. Guelfucci, F., Clay, E., Aballéa, S., Lassalle, R., Moore, N., Toumi, M.: Impact of therapy escalation on ambulatory care costs among patients with type 2 diabetes in France. BMC Endocr. Disord. 13, 15 (2013)

35. Hanaire, H., Attali, C., Lecointre, B., Fraysse, M., Gouet, D., Babel, M.R., Charbonnel, B., Sarkozy, F., Gourmelen, J., Detournay, B.: Determinants of the cost of initiation of insulin therapy type 2 diabetic patients in France: possible approaches to optimization. Sante Publique 28(6), 781-789 (2016)

36. Charbonnel, B., Simon, D., Dallongeville, J., Bureau, I., Dejager, S., Levy-Bachelot, L., Gourmelen, J., Detournay, B.: Direct medical costs of type 2 diabetes in France: an insurance claims database analysis. Pharmacoecon. Open. 2(2), 209-219 (2018)

37. Rapp, T., Andrieu, S., Chartier, F., Deberdt, W., Reed, C., Belger, M., Vellas, B.: Resource use and cost of Alzheimer's Disease in France: 18 -month results from the GERAS observational study. Value Health 21(3), 295-303 (2018)

38. Amorosi, S.L., Armstrong, S., Da Deppo, L., Garfield, S., Stein, K.: The budget impact of left atrial appendage closure compared with adjusted-dose warfarin and dabigatran etexilate for stroke prevention in atrial fibrillation. Europace 16(8), 1131-1136 (2014)

39. Bock, J.O., Brettschneider, C., Seidl, H., Bowles, D., Holle, R., Greiner, W., König, H.H.: Calculation of standardised unit costs from a societal perspective for health economic evaluation. Gesundheitswesen 77(1), 53-61 (2015)

40. Freund, T., Peters-Klimm, F., Boyd, C.M., Mahler, C., Gensichen, J., Erler, A., Beyer, M., Gondan, M., Rochon, J., Gerlach, F.M., Szecsenyi, J.: Medical assistant-based care management for high-risk patients in small primary care practices: a cluster 
randomized clinical trial. Ann. Intern. Med. 164(5), 323-330 (2016)

41. Grupp, H., König, H.H., Konnopka, A.: Health care utilisation and costs in the general population in Germany. Health Policy 120(2), 159-169 (2016)

42. Icks, A., Claessen, H., Strassburger, K., Waldeyer, R., Chernyak, N., Jülich, F., Rathmann, W., Thorand, B., Meisinger, C., Huth, C., Rückert, I.M., Schunk, M., Giani, G., Holle, R.: Patient time costs attributable to healthcare use in diabetes: results from the population-based KORA survey in Germany. Diabet. Med. 30(10), 1245-1249 (2013)

43. Jacob, L., von Vultee, C., Kostev, K.: Prescription patterns and the cost of antihyperglycemic drugs in patients with type 2 diabetes mellitus in Germany. J. Diabetes Sci. Technol. 11(1), 123-127 (2017)

44. Köster, I., Huppertz, E., Hauner, H., Schubert, I.: Costs of Diabetes Mellitus (CoDiM) in Germany, direct per-capita costs of managing hyperglycaemia and diabetes complications in 2010 compared to 2001. Exp. Clin. Endocrinol. Diabetes 122(9), 510-516 (2014)

45. Müller, N., Heller, T., Freitag, M.H., Gerste, B., Haupt, C.M., Wolf, G., Müller, U.A.: Healthcare utilization of people with type 2 diabetes in Germany: an analysis based on health insurance data. Diabet. Med. 32(7), 951-957 (2015)

46. Neubauer AS, Haritoglou C, Ulbig MW. [Cost comparison of licensed intravitreal therapies for insufficiently anti-VEGF responding fovea involving diabetic macular edema in Germany]. Klin. Monbl. Augenheilkd. (2018) [epub ahead of print]

47. Schnell, O., Erbach, M.: Impact of a reduced error range of SMBG in insulin-treated patients in Germany. J. Diabetes Sci. Technol. 8(3), 479-482 (2014)

48. Ulrich, S., Holle, R., Wacker, M., Stark, R., Icks, A., Thorand, B., Peters, A., Laxy, M.: Cost burden of type 2 diabetes in Germany: results from the population-based KORA studies. BMJ Open 6(11), e012527 (2016)

49. Wilke, T., Böttger, B., Berg, B., Groth, A., Botteman, M., Yu, S., Fuchs, A., Maywald, U.: Healthcare burden and costs associated with urinary tract infections in type 2 diabetes mellitus patients: an analysis based on a large sample of 456,586 German patients. Nephron. 132(3), 215-226 (2016)

50. Wolff, J., McCrone, P., Patel, A., Auber, G., Reinhard, T.: A time study of physicians' work in a German university eye hospital to estimate unit costs. PLoS ONE 10(3), e0121910 (2015)

51. Afonso, M., Ryan, F., Pitcher, A., Lew, E.: Evaluating drug cost per responder and number needed to treat associated with lixisenatide on top of glargine when compared to rapid-acting insulin intensification regimens on top of glargine, in patients with type 2 diabetes in the UK, Italy, and Spain. J. Med. Econ. 20(6), 633-639 (2017)

52. Bruno, G., Pagano, E., Rossi, E., Cataudella, S., De Rosa, M., Marchesini, G., Miccoli, R., Vaccaro, O., Bonora, E.: Incidence, prevalence, costs and quality of care of type 1 diabetes in Italy, age 0-29 years: The population-based CINECA-SID ARNO Observatory, 2002-2012. Nutr. Metab. Cardiovasc. Dis. 26(12), 1104-1111 (2016)

53. Calò L, Gargaro A, De Ruvo E, Palozzi G, Sciarra L, Rebecchi M, Guarracini F, Fagagnini A, Piroli E, Lioy E, Chirico A. Economic impact of remote monitoring on ordinary follow-up of implantable cardioverter defibrillators as compared with conventional in-hospital visits. A single-center prospective and randomized study. J. Interv. Card. Electrophysiol. 37(1), 69-78 (2013)

54. Degli Esposti, L., Saragoni, S., Buda, S., Sturani, A., Degli, E.E.: Glycemic control and diabetes-related health care costs in type 2 diabetes; retrospective analysis based on clinical and administrative databases. Clinicoecon. Outcomes Res. 5, 193-201 (2013)
55. Degli Esposti, L., Saragoni, S., Buda, S., Degli, E.E.: Clinical outcomes and health care costs combining metformin with sitagliptin or sulphonylureas or thiazolidinediones in uncontrolled type 2 diabetes patients. Clinicoecon. Outcomes Res. 6, 463-472 (2014)

56. Demurtas J, Alba N, Rigon G, Nesoti MV, Bovo C, Vaona A. Epidemiological trends and direct costs of diabetes in a Northern Italy area: 2012 health administrative records analysis LHT n. 20 Verona. Prim. Care Diabetes 11(6), 570-576 (2017)

57. Germini F, Veronese G, Marcucci M, Coen D, Ardemagni D, Montano N, Fabbri A; SIMEU Study Group. COPD exacerbations in the emergency department: epidemiology and related costs. a retrospective cohort multicentre study from the Italian Society of Emergency Medicine (SIMEU). Eur. J. Intern. Med. 51, 74-79 (2018)

58. Giorda CB, Rossi MC, Ozzello O, Gentile S, Aglialoro A, Chiambretti A, Baccetti F, Gentile FM, Romeo F, Lucisano G, Nicolucci A; HYPOS- Study Group of AMD. Healthcare resource use, direct and indirect costs of hypoglycemia in type 1 and type 2 diabetes, and nationwide projections; results of the HYPOS-1 study. Nutr. Metab. Cardiovasc. Dis. 27(3), 209-216 (2017)

59. Ippolito, A., Boni, S., Cinque, E., Greco, A., Salis, S.: Using time-driven activity-based costing to establish a tariff system for home health care services. J. Healthc. Manag. 61(6), 436447 (2016)

60. Marchesini, G., Bernardi, D., Miccoli, R., Rossi, E., Vaccaro, O., De Rosa, M., Bonora, E., Bruno, G.: Under-treatment of migrants with diabetes in a universalistic health care system: the ARNO Observatory. Nutr. Metab. Cardiovasc. Dis. 24(4), 393-399 (2014)

61. Pagano, E., De Rosa, M., Rossi, E., Cinconze, E., Marchesini, G., Miccoli, R., Vaccaro, O., Bonora, E., Bruno, G.: The relative burden of diabetes complications on healthcare costs: the population-based CINECA-SID ARNO Diabetes Observatory. Nutr. Metab. Cardiovasc. Dis. 26(10), 944-950 (2016)

62. Parekh, W., Streeton, S.E., Baker-Knight, J., Montagnoli, R., Nicoziani, P., Marchesini, G.: The Economic burden of insulinrelated hypoglycemia in adults with diabetes: an analysis from the perspective of the Italian healthcare system. Diabetes Ther. 9(3), 1037-1047 (2018)

63. Pirolo, R., Bettiol, A., Bolcato, J., Franchin, G., Deambrosis, P., Paccagnella, A., Giusti, P., Chinellato, A.: Cost-of-illness della patologia diabetic in Italia: focus sul paziente con diabete di tipo 2. Global Reg. Health Technol. Assess. 3(1), 32-41 (2016)

64. Ravasio, R., Pisarra, P., Porzio, R., Comaschi, M.: Economic evaluation of canagliflozin versus glimepiride and sitagliptin in dual therapy with metformin for the treatment of type 2 diabetes in Italy. Global Reg. Health Technol. Assess. 3(2), 92-101 (2016)

65. Schuetz, C.A., Alperin, P., Guda, S., van Herick, A., Cariou, B., Eddy, D., Gumprecht, J., Nicolucci, A., Schwarz, P., Wareham, N.J., Witte, D.R., Smith, U.: A standardized vascular disease health check in Europe: a cost-effectiveness analysis. PLoS ONE 8(7), e66454 (2013)

66. Tuppin, P., Rudant, J., Constantinou, P., Gastaldi-Ménager, C., Rachas, A., de Roquefeuil, L., Maura, G., Caillol, H., Tajahmady, A., Coste, J., Gissot, C., Weill, A., Fagot-Campagna, A.: Value of a national administrative database to guide public decisions: from the système national d'information interrégimes de l'Assurance Maladie (SNIIRAM) to the système national des données de santé (SNDS) in France. Rev. Epidemiol. Sante Publique 65(Suppl. 4), S149-S167 (2017)

67. Bezin, J., Duong, M., Lassalle, R., Droz, C., Pariente, A., Blin, P., Moore, N.: The national healthcare system claims databases in 
France, SNIIRAM and EGB: powerful tools for pharmacoepidemiology. Pharmacoepidemiol. Drug Saf. 26(8), 954-962 (2017)

68. Seidl, H., Hunger, M., Meisinger, C., Kirchberger, I., Kuch, B., Leidl, R., Holle, R.: The 3-year cost-effectiveness of a nursebased case management versus usual care for elderly patients with myocardial infarction: results from the KORINNA followup study. Value Health 20(3), 441-450 (2017)

69. Laxy, M., Stark, R., Peters, A., Hauner, H., Holle, R., Teuner, C.M.: The non-linear relationship between bmi and health care costs and the resulting cost fraction attributable to obesity. Int. J. Environ. Res. Public Health 14(9), 984 (2017)

70. Barnett, A.H., Arnoldini, S., Hunt, B., Subramanian, G., Hoxer, C.S.: Switching from sitagliptin to liraglutide to manage patients with type 2 diabetes in the UK: a long-term cost-effectiveness analysis. Diabetes Obes. Metab. 20(8), 1921-1927 (2018)

71. Charokopou, M., McEwan, P., Lister, S., Callan, L., Bergenheim, K., Tolley, K., Postema, R., Townsend, R., Roudaut, M.: Costeffectiveness of dapagliflozin versus dpp-4 inhibitors as an addon to metformin in the treatment of type 2 diabetes mellitus from a UK healthcare system perspective. BMC Health Serv. Res. 15, 496 (2015)

72. Charokopou, M., McEwan, P., Lister, S., Callan, L., Bergenheim, K., Tolley, K., Postema, R., Townsend, R., Roudaut, M.: The cost-effectiveness of dapagliflozin versus sulfonylurea as an addon to metformin in the treatment of type 2 diabetes mellitus. Diabet. Med. 32(7), 890-898 (2015)

73. Chuang, L.H., Verheggen, B.G., Charokopou, M., Gibson, D., Grandy, S., Kartman, B.: Cost-effectiveness analysis of exenatide once-weekly versus dulaglutide, liraglutide, and lixisenatide for the treatment of type 2 diabetes mellitus: an analysis from the UK NHS perspective. J. Med. Econ. 19(12), 1127-1134 (2016)

74. Davies MJ, Glah D, Chubb B, Konidaris G, McEwan P. Cost effectiveness of IDegLira vs. alternative basal insulin intensification therapies in patients with type 2 diabetes mellitus uncontrolled on basal insulin in a UK setting. Pharmacoeconomics 34(9), 953-966 (2016)

75. Dawoud, D., Fenu, E., Higgins, B., Wonderling, D., Amiel, S.A.: Basal insulin regimens for adults with type 1 diabetes mellitus: a cost-utility analysis. Value Health 20(10), 1279-1287 (2017)

76. Dilla, T., Alexiou, D., Chatzitheofilou, I., Ayyub, R., Lowin, J., Norrbacka, K.: The cost-effectiveness of dulaglutide versus liraglutide for the treatment of type 2 diabetes mellitus in Spain in patients with $B M I \geq 30 \mathrm{~kg} / \mathrm{m} 2$. J. Med. Econ. 20(5), 443-452 (2017)

77. Drummond, R., Malkin, S., Du Preez, M., Lee, X.Y., Hunt, B.: The management of type 2 diabetes with fixed-ratio combination insulin degludec/liraglutide (IDegLira) versus basal-bolus therapy (insulin glargine U100 plus insulin aspart): a short-term cost-effectiveness analysis in the UK setting. Diabetes Obes. Metab. 20(10), 2371-2378 (2018)

78. Evans, M., Achha, S., Neslusan, C.: Cost of glycemic target achievement with sodium glucose co-transporter 2 inhibitors in patients with type 2 diabetes in the UK. Diabetes Ther. 8(5), 1175-1185 (2017)

79. Evans, M., Chubb, B., Gundgaard, J.: Cost-effectiveness of insulin degludec versus insulin glargine in adults with type 1 and type 2 diabetes mellitus. Diabetes Ther. 8(2), 275-291 (2017)

80. Evans, M., McEwan, P., Foos, V.: Insulin degludec early clinical experience: does the promise from the clinical trials translate into clinical practice-a case-based evaluation. J. Med. Econ. 18(2), 96-105 (2015)

81. Evans M, McEwan P, O'Shea R, George L. A retrospective, casenote survey of type 2 diabetes patients prescribed incretin-based therapies in clinical practice. Diabetes Ther. 4(1), 27-40 (20173

82. Evans M, Mehta R, Gundgaard J, Chubb B. Cost-effectiveness of insulin degludec vs. insulin glargine u100 in type 1 and type
2 diabetes mellitus in a UK setting. Diabetes Ther. 9(5), 1919 1930 (2018)

83. Evans, M., Wolden, M., Gundgaard, J., Chubb, B., Christensen, T.: Cost-effectiveness of insulin degludec compared with insulin glargine for patients with type 2 diabetes treated with basal insulin: from the UK health care cost perspective. Diabetes Obes. Metab. 16(4), 366-375 (2014)

84. Evans, M., Wolden, M., Gundgaard, J., Chubb, B., Christensen, T.: Cost-effectiveness of insulin degludec compared with insulin glargine in a basal-bolus regimen in patients with type 1 diabetes mellitus in the UK. J. Med. Econ. 18(1), 56-68 (2015)

85. Ferrario MG, Lizán L, Montagnoli R, Ramírez de Arellano A. Liraglutide vs. sitagliptin add-on to metformin treatment for type 2 diabetes mellitus: short-term cost-per-controlled patient in Italy. Prim. Care Diabetes 10(3), 220-226 (2016)

86. Fonseca, T., Clegg, J., Caputo, G., Norrbacka, K., Dilla, T., Alvarez, M.: The cost-effectiveness of exenatide once weekly compared with exenatide twice daily and insulin glargine for the treatment of patients with type two diabetes and body mass index $\geq 30 \mathrm{~kg} / \mathrm{m} 2$ in Spain. J. Med. Econ. 16(7), 926-938 (2013)

87. Gordon, J., McEwan, P., Hurst, M., Puelles, J.: The cost-effectiveness of alogliptin versus sulfonylurea as add-on therapy to metformin in patients with uncontrolled type 2 diabetes mellitus. Diabetes Ther. 7(4), 825-845 (2016)

88. Hunt, B., Kragh, N., McConnachie, C.C., Valentine, W.J., Rossi, M.C., Montagnoli, R.: Long-term cost-effectiveness of two glp-1 receptor agonists for the treatment of type 2 diabetes mellitus in the italian setting: liraglutide versus lixisenatide. Clin. Ther. 39(7), 1347-1359 (2017)

89. Hunt, B., Vega-Hernandez, G., Valentine, W.J., Kragh, N.: Evaluation of the long-term cost-effectiveness of liraglutide vs lixisenatide for treatment of type 2 diabetes mellitus in the UK setting. Diabetes Obes. Metab. 19(6), 842-849 (2017)

90. Hunt, B., Ye, Q., Valentine, W.J., Ashley, D.: Evaluating the long-term cost-effectiveness of daily administered glp-1 receptor agonists for the treatment of type 2 diabetes in the United Kingdom. Diabetes Ther. 8(1), 129-147 (2017)

91. Iannazzo, S., Mannucci, E., Reifsnider, O., Maggioni, A.P.: Cost-effectiveness analysis of empagliflozin in the treatment of patients with type 2 diabetes and established cardiovascular disease in Italy, based on the results of the EMPA-REG OUTCOME study. Farmeconomia 18(1), 43-53 (2017)

92. Liebl A, Seitz L, Palmer AJ. Health economics analysis of insulin aspart vs. regular human insulin in type 2 diabetes patients, based on observational real life evidence from general practices in Germany. Exp. Clin. Endocrinol. Diabetes. 122(9), 517-522 (2014)

93. Mezquita-Raya P, Darbà J, Ascanio M, Ramírez de Arellano A. Cost-effectiveness analysis of insulin degludec compared with insulin glargine u100 for the management of type 1 and type 2 diabetes mellitus: from the Spanish National Health System perspective. Expert. Rev. Pharmacoecon. Outcomes Res. 17(6), 587-595 (2017)

94. Mezquita-Raya P, Ramírez de Arellano A, Kragh N, VegaHernandez G, Pöhlmann J, Valentine WJ, Hunt B. Liraglutide versus lixisenatide: long-term cost-effectiveness of glp-1 receptor agonist therapy for the treatment of type 2 diabetes in Spain. Diabetes Ther. 8(2), 401-415 (2017)

95. Mezquita-Raya P, Pérez A, Ramírez de Arellano A, Briones T, Hunt B, Valentine WJ. Incretin therapy for type 2 diabetes in Spain: a cost-effectiveness analysis of liraglutide versus sitagliptin. Diabetes Ther. 4(2), 417-430 (2013)

96. Morales, C., de Luis, D., de Arellano, A.R., Ferrario, M.G., Lizán, L.: Cost-effectiveness analysis of insulin detemir compared to neutral protamine Hagedorn (NPH) in patients with type 
1 and type 2 diabetes mellitus in Spain. Diabetes Ther. 6(4), 593-610 (2015)

97. Abad Paniagua, E.J., Casado Escribano, P., Fernández Rodriguez, J.M., Morales Escobar, F.J., Betegón Nicolás, L., SánchezCovisa, J., Brosa, M.: Cost-effectiveness analysis of dapagliflozin compared to DPP4 inhibitors and other oral antidiabetic drugs in the treatment of type-2 diabetes mellitus in Spain. Aten. Primaria 47(8), 505-513 (2015)

98. Pérez A, Mezquita Raya P, Ramírez de Arellano A, Briones T, Hunt B, Valentine WJ. Cost-effectiveness analysis of incretin therapy for type 2 diabetes in Spain: $1.8 \mathrm{mg}$ liraglutide versus sitagliptin. Diabetes Ther. 6(1), 61-74 (2015)

99. Pollock, R.F., Chubb, B., Valentine, W.J., Heller, S.: Evaluating the cost-effectiveness of insulin detemir versus neutral protamine Hagedorn insulin in patients with type 1 or type 2 diabetes in the UK using a short-term modeling approach. Diabetes Metab. Syndr. Obes. 2018(11), 217-226 (2018)

100. Pollock RF, Valentine WJ, Marso SP, Gundgaard J, Hallén N, Hansen LL, Tutkunkardas D, Buse JB; DEVOTE Study Group. DEVOTE 5: evaluating the short-term cost-utility of insulin degludec versus insulin glargine u100 in basal-bolus regimens for type 2 diabetes in the UK. Diabetes Ther. 9(3), 1217-1232 (2018)

101. Roussel, R., Martinez, L., Vandebrouck, T., Douik, H., Emiel, P., Guery, M., Hunt, B., Valentine, W.J.: Evaluation of the long-term cost-effectiveness of liraglutide therapy for patients with type 2 diabetes in France. J. Med. Econ. 19(2), 121-134 (2016)

102. Russell-Jones, D., Heller, S.R., Buchs, S., Sandberg, A., Valentine, W.J., Hunt, B.: Projected long-term outcomes in patients with type 1 diabetes treated with fast-acting insulin aspart vs conventional insulin aspart in the UK setting. Diabetes Obes. Metab. 19(12), 1773-1780 (2017)

103. Valentine, W.J., Curtis, B.H., Pollock, R.F., Van Brunt, K., Paczkowski, R., Brändle, M., Boye, K.S., Kendall, D.M.: Is the current standard of care leading to cost-effective outcomes for patients with type 2 diabetes requiring insulin? A long-term health economic analysis for the UK. Diabetes Res. Clin. Pract. 109(1), 95-103 (2015)

104. Valentine WJ, Van Brunt K, Boye KS, Pollock RF. Treating type 1 diabetes mellitus with a rapid-acting analog insulin regimen vs. regular human insulin in Germany: a long-term cost-effectiveness evaluation. Appl. Health Econ. Health Policy. 16(3), $357-366$ (2018)

105. Vega-Hernandez, G., Wojcik, R., Schlueter, M.: Cost-Effectiveness of liraglutide versus dapagliflozin for the treatment of patients with type 2 diabetes mellitus in the UK. Diabetes Ther. 8(3), 513-530 (2017)

106. Disoteo, O., Grimaldi, F., Papini, E., Attanasio, R., Tonutti, L., Pellegrini, M.A., Guglielmi, R., Borretta, G.: State-of-theart review on diabetes care in Italy. Ann. Global Health 81(6), 803-813 (2015)

107. Vukovic, V., Favaretti, C., Ricciardi, W., de Waure, C.: Health technology assessment evidence on e-health/m-health technologies: evaluating the transparency and thoroughness. Int. J. Technol. Assess. Health Care 34(1), 87-96 (2018)

108. Adam, T., Koopmanschap, M.A., Evans, D.B.: Cost-effectiveness analysis: can we reduce variability in costing methods? Int. J. Technol. Assess. Health Care 19(2), 407-420 (2003)

109. Gyldmark M, Lampe K, Ruof J, Pöhlmann J, Hebborn A, Kristensen FB. Is the EUnetHTA HTA Core Model ${ }^{\circledR}$ fit for purpose? Evaluation from an industry perspective. Int. J. Technol. Assess. Health Care 34(5), 458-463 (2018) [epub ahead of print]

110. Neumann, P.J.: Costing and perspective in published cost-effectiveness analysis. Med. Care 47(7 Suppl. 1), S28-S32 (2009)

Publisher's Note Springer Nature remains neutral with regard to jurisdictional claims in published maps and institutional affiliations. 